\title{
COCHLEAR IMPLANTATION: MY EXPERIENCE
}

\author{
T. Shankar ${ }^{1}$
}

1Professor, Department of ENT, Osmania Medical College/Govt. ENT Hospital, Koti, Hyderabad.

\section{ABSTRACT}

Cochlear implant is a small, surgically implanted complex electronic device that can help to provide a sense of sound to a person with severe to profound sensorineural hearing loss. This type of hearing loss, typically involves damage to hair cells in the cochlea, as a result sound cannot reach the auditory nerve which usually receives information from hair cells. A cochlear implant skips the damaged hair cells and to stimulate the auditory nerve directly. An implant does not restore normal hearing, instead it can give a deaf person a useful representation of sounds in the environment and help him or her to understand speech. I am here presenting this article in relation to the indications, intraoperative and postoperative complications of cochlear implantation in our institute since January 2013. Children who receive implants at earlier age, outperform their peers who are implanted at a later age. This is reflected in all the areas of speech and language development.

\section{KEYWORDS}

Auditory Verbal Therapy, Cochlear Implant, Hair Cells, Sensorineural Deafness, Microphone.

HOW TO CITE THIS ARTICLE: T. Shankar. “Cochlear Implantation: My Experience.” Journal of Evolution of Medical and Dental Sciences 2015; Vol. 4, Issue 98, December 07; Page: 16315-16319, DOI: 10.14260/jemds/2015/2408

\section{INTRODUCTION}

Early identification of hearing defect is the most important factor for timely intervention in the management of congenitally hearing impaired children. Cochlear implant has become a routine surgery in the united states and worldwide for the management of severe to profound sensor neural hearing loss the team concept in cochlear implant surgery, evaluation allows for an exchange of information between the surgeon and other members of the implant and rehabilitation process including speech and language therapists, audiologists, psychologists and social workers the patient may first be seen and identified as an implant candidate by an audiologist, various issues are taken into consideration including medical aspects of the patients history, the radiological studies and the audio logical evaluation.

The audiologist measures the patients hearing with and without hearing aids, evaluation with pure tone audiometry and Auditory Brainstem Response (ABR) testing is often performed. Otoacoustic Emission (OAE) testing complements these studies. A CT scan is taken to evaluate the status of the cochlea and to establish the presence of a patent cochlea or mondini dysplasia, a common cavity, an ossified cochlea and enlarged vestibular aqueduct some cases an MRI is used, in children and young adults speech and language evaluation finally a psychosocial evaluation is completed.

Financial or Other, Competing Interest: None.

Submission 09-11-2015, Peer Review 10-11-2015,

Acceptance 27-11-2015, Published 04-12-2015.

Corresponding Author:

Dr. T. Shankar

Flat No. 401, Plot No. $59 \& 62$,

GK Rishitha Mari Gold Apts,

Hasthinapuri Colony,

Sainikpuri-94,

Secunderabad.

E-mail: drshankar_ms@yahoo.com

DOI:10.14260/jemds/2015/2408

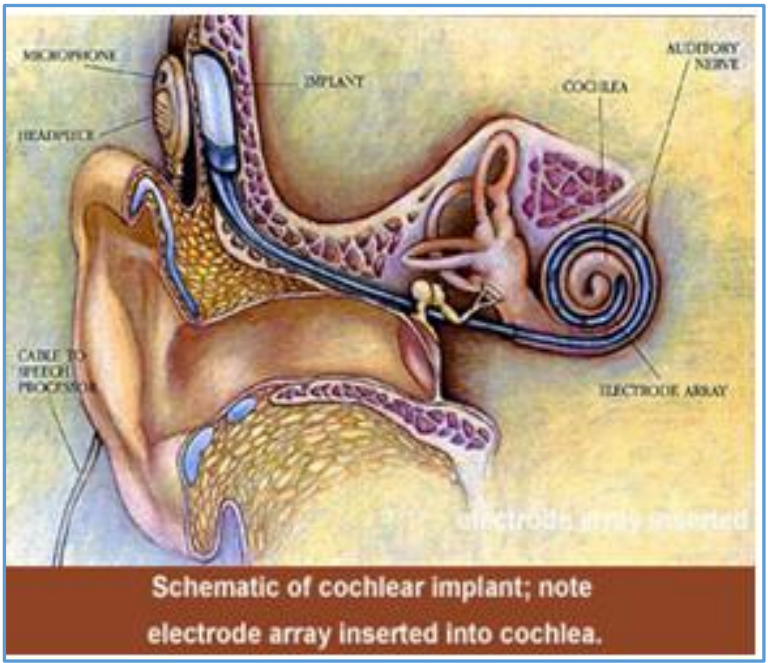

Fig. 1: Cochlea with Implant In-Situ

The cochleostomy must be made inferior and slightly anterior to the round window rather than anterior to ensure scala tympani insertion and to decrease the likelihood of insertion induced intracochlear damage, particularly the basal membrane and organ of corti during electrode insertion.

\section{Parts of the Cochlear Implant}

\section{External}

- A Microphone, which picks up sound from the environment.

- A Speech Processor, which selects and arranges sounds picked by the microphone.

- A Transmitter, which is a coil held in position by a magnet placed behind the external ear, which transmits power and the processed sound signals across the skin to the internal device by electromagnetic induction.

\section{Internal}

- A receiver and stimulator secured in bone beneath the skin, which converts the signals into electric impulses and sends them through an internal cable to electrodes. 


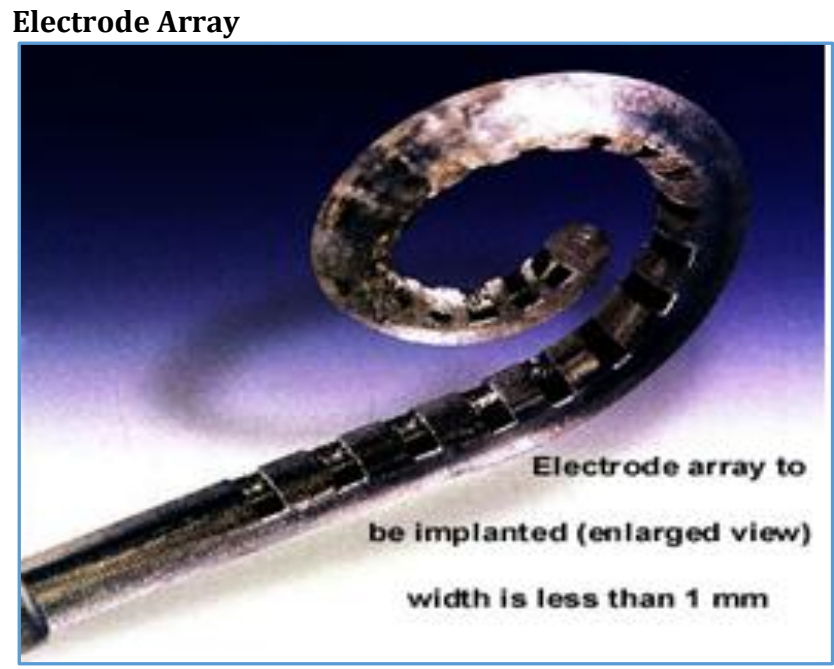

Fig. 2: (Electrode Array)

The array is made from a type of silicone rubber, while the electrodes are made of platinum or a similar highly conductive material. It is connected to the internal receiver on one end and is inserted into the cochlea through cochleostomy. (The cochlea winds its way around the auditory nerve, which is ton topically organized as in the basal membrane). When an electric current is routed to an intracochlear electrode, an impulse generated to the nerves in scala tympani and then directly to the brain through the auditory nerve system.

The insertion depth is another important factor, the mean length of human cochlea is $33-36 \mathrm{~mm}$, due to some physical limitation. The implants do not reach to the apical tip when inserted, but it may reach up to $25 \mathrm{~mm}(0.98)$ in which corresponds to a ton topical frequencies of $400-6000 \mathrm{~Hz}$., there is a strong research in this direction and the best sounding implant can be subjective from patient to patient. The number of channels is not a primary factor up on which a manufacturer chosen, the signal processing algorithm is also another important factor.

\section{Indications}

- The main indication for cochlear implant is severe to profound SN hearing loss, in both ear that is not adequately treated with hearing aids.

- Congenital hearing loss and prelingual deafness.

- Acquired hearing loss and postlingual deafness.

- Severe hearing loss that can be aided and deteriorates to profound hearing loss in children and adults.

\section{Contraindications}

- Deafness due to lesions of the auditory nerve or brain stem.

- $\quad$ Chronic infections of the middle ear cavity and mastoid or tympanic membrane perforation.

- The absence of cochlea development is an absolute contraindication.

- Certain medical conditions like specific hematologic, cardiac, pulmonary conditions.

- The lack of realistic expectations regarding the benefits of cochlear implant.

- A lack of strong desire to develop enhanced oral communication skills.

\section{Benefits of Cochlear Implants}

- $\quad$ Speech and language developed at the right age.

- Hears clearly in noisy environments.

- Starts enjoying the world of new sounds.

- People speak at normal hearing level.

- Start talking on phone.

- Communicate better with teachers, friends and family members.

- Develop more confidence in different social situations.

- They enjoy the music.

- Can figure out the direction of the sound from approaching vehicle.

\section{Surgical Procedures}

There are two techniques for cochlear implant surgery.

1. Mastoidectomy - posterior tympanotomy approach.

2. End aural approach and Transcanal technique (Veria technique).

\section{Mastoidectomy - Posterior Tympanotomy Approach}

Under aseptic precautions under general anesthesia, an incision is made in the crease behind the ear, skin and soft tissue elevated, mastiodectomy done. This allows to access the inner ear without disturbing the ear canal or ear drum.

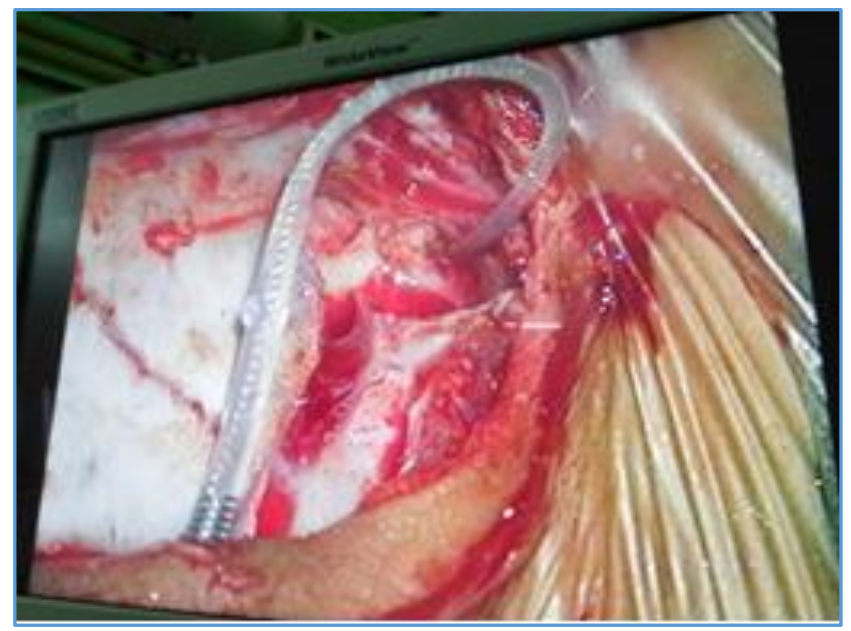

Fig. 3: (Posterior Tympanotomy Approach)

A small opening is made into the cochlea, and the implant electrode is threaded in as far as possible. The incision is closed with absorbable stitches. Antiseptic dressing done. Patient usually leaves the hospital on $5^{\text {th }}$ postoperative day under antibiotic coverage. The initial activation of the device and placement of the external equipment is performed 3 weeks after surgery.

(Veria Technique). The End Aural Approach and the Transcanal Technique

This is a nonmastoidectomy technique, which is done through the end aural route for the cochleostomy with a transcanal tunnel drilled in the posterior canal wall. 


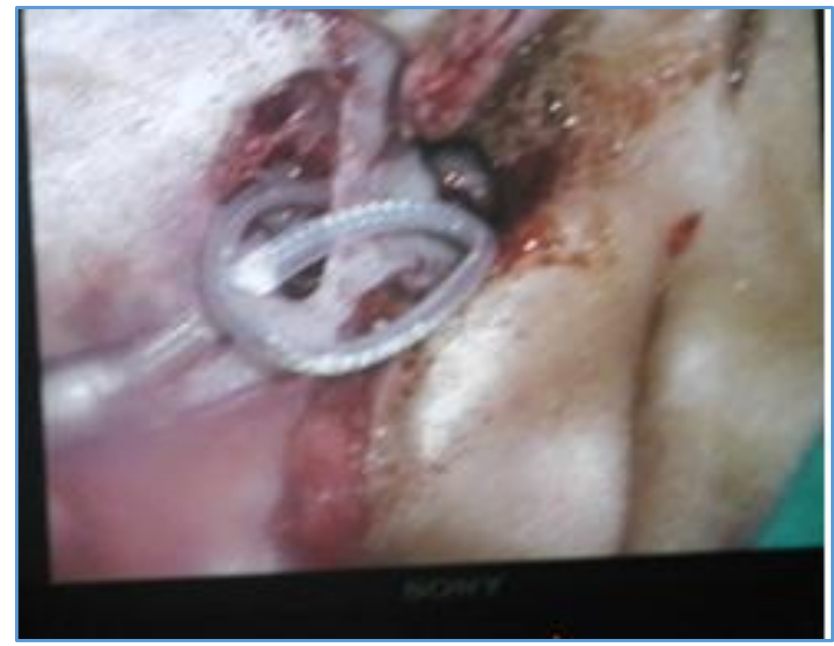

Fig. 4 (Varia Technique)

It is a more effective and less complicated as compared to the conventional technique. This technique is simple, is precise thereby decreasing trauma to the facial nerve, helps in faster healing and earlier fitting of the processor.

\section{Post Cochlear Implant}

After cochlear implant surgery, rehabilitation is essential, can be imparted at the hospital or auditory rehabilitation centers, the patient needs to know learning or relearning techniques. Hearing through the cochlear implant is very different from normal hearing or hearing through hearing aids, the cochlear implants directly stimulate the auditory nerve, then sends signals to brain which recognize them as sounds, over the time, the patient learns to hear and enjoy music, conversations and environmental sounds.

\section{METHODS AND MATERIALS}

This is a prospective study comprising of 23 patients who underwent cochlear implantation during January 2013 to August 2015 in Govt. ENT Hospital, Koti/Osmania Medical College, Hyderabad. All the cases were operated by corresponding author under supervision of mentor surgeon for cochlear implantation. These patients were presented with severe to profound congenital sensorineural deafness. All the patients were under 02 years of age, except 02 patients; 01 male child was operated at the age of 06 years and 01 female patient was operated for postlingual deafness at the age of 32 years. All the patients were subjected to detailed clinical and audiological evaluation for fitness for cochlear implant surgery. Since this operation is covered under Aarogyasri (Free of cost by State Government), in this program the maximum age limit is 02 years; hence, my study is limited to children under 02 years of age. All other relevant investigations were done for fitness for general anesthesia. Out of 23 cases, 18 cases were operated by posterior tympanotomy approach and 05 cases were operated by Veria technique. Intraoperative and postoperative complications were noticed and analyzed. AVT therapy was monitored for all the patients.

\section{SURGICAL PROCEDURE}

All the patients are operated under GA. The patient's ear is cleaned as in the case of the mastoidectomy with complete removal of debris. Most of my case are operated through postaural route with posterior tympanotomy approach. In this procedure, the postaural incision is given on the side of the surgery. This incision extends up onto the scalp like a lazy $\mathrm{S}$ shape to make stable bed for implant. After exposure of the mastoid cortex and temporal bone, cortical mastoidectomy performed, short process of incus identified; then the posterior tympanotomy done in the triangle between facial nerve, chorda tympani nerve and small piece of bone left near the tip of the short process of incus, the incudostapedial joint identified just below and behind the oval window the round window niche is identified. At the junction of basal turn of cochlea and round window niche, the cochleostomy site is marked, sub-periosteal pockets were made superiorly and anteriorly to house the implant and ground electrode (If present separate from implant).

The bed for the cochlear implant is marked in the most stable part of the squamous temporal bone. The bed is drilled to the depth to the endosteum is seen, margins of the bed are made at the right angles which prevent the migration of the implant, then the implant is fixed in the bed. Cochleostomy is made in the anteroinferior part of the round window niche; slowly the electrodes are inserted into the cochlea tome, periosteum tissue placed around the electrode. Wound was closed in layers after ART, NRT and ESRT done by the audiologist.

In Veria technique the surgical procedure varies from above technique. After preparation of the ear, an end aural incision is given. Posteriorly based skin flap is elevated, which is supplied by the posterior auricular artery. The underlying temporalis muscle flap (anterior based flap) is elevated to expose the underlying temporal bone. The Han's flap is the posteriorly based periosteal flap, is located in the suprameatal junction, this covers the electrode in the suprameatal well.(1) After locating the suprameatal line, the suprameatal well is drilled down not more than $1.5 \mathrm{~mm}$ deep, keeping the edges of the well undermined. This keeps the electrode in place, canal wall incisions are made. The tympanomeatal flap is elevated. This gives a wider visualization of the round window.

The tunnel is made in the posterior canal wall using a specially designed hand piece, which has a guide and cutting drill bit at a distance of $4 \mathrm{~mm}$. The diameter of the tunnel drilled is of $1.4 \mathrm{~mm}$. The entry of the tunnel at the suprameatal well is at 11 o'clock and exit medially in the middle ear at 9 o'clock. Good irrigation is required. There can be heat dissipation through the mastoid air cell system towards the facial nerve. The electrode passing through this tunnel is safely surrounded by bone on all sides, separated from the mastoid air cell system. The remaining procedure is same as the above technique.

In my study I found that the Veria technique is safe, which is done through end aural route for the cochleostomy with a transcanal tunnel drilled in the posterior canal wall. This technique is more useful in children with small facial recess, cochlear rotation and cochlear malformation. This technique is simple, helps faster healing. It is precise thereby minimizing trauma to the facial nerve. Though the conventional technique has been successful, it is more time consuming and is prone to more complications, especially the facial nerve injury.

\section{RESULTS}

In my series after observing, 06 cases and assisting 13 cases I have operated, 23 cochlear implant surgeries under the supervision of mentor surgeon. Among 23 cases, 10 cases were male children and 11 cases were female children under 02 years of age, 01 female patient at the age of 32 years and 01 male patient at the age of 06 years. Among all the cases, 01 case had complication of electrode array displaced and it was found in the Eustachian tubal orifice on postop x-ray. 


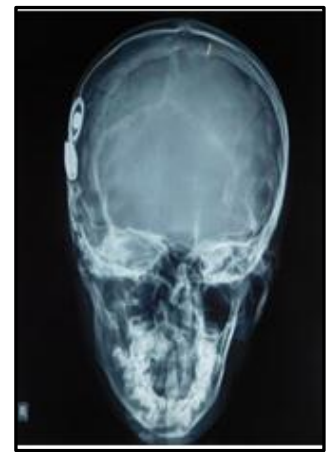

Fig. 5

Electrode Array in the Cochlea
(Postop X-Ray)

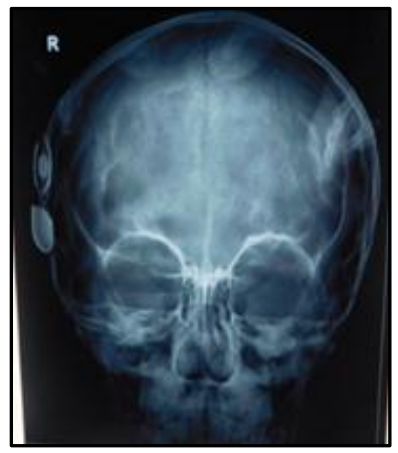

Fig. 6

(Postop X-Ray)

Electrode Array in

Eustachian Tube
This case was taken up for revision surgery and the electrode array was placed into the cochlea. All my cases were operated under general anesthesia. Among this 18 patients were operated by conventional technique and 05 patients were operated by Veria technique. In my study, I found that the Veria technique is more safe and comfortable with less complications, as in my series I have encountered very minimal complications. All my cases are doing well in AVT therapy. Some of the children are going to normal school with good speech and language development. Still our institute is carrying out the cochlear implant program under Aarogyasri scheme for children of BPI families.

\section{DISCUSSION}

The surgical placement of cochlear implant has been performed for over 20 years, newer implant designs and surgical techniques allow us to place these implants with very few complications and excellent cosmetic results. In 1957, Djourno and Eyries made the observation that activation of the auditory nerve with an electrified device provides auditory stimulation in a congenital deaf patient. This observation is considered the seminal observations that paved with way for modern cochlear implantation in 1963 Doyle and Doyle's early experiments in scalatympani implantation proceeded the first Housel $3 \mathrm{~m}$ single channel implant in 1972.(2) multichannel devices introduced in 1984 have replaced single channel devices by virtue of improved speech recognition capabilities.

To be born deaf can have the most devastating consequences, detected late, counseled improperly, inadequately intervened, many children grow up without speaking and hearing like their peers. Now of course there is a way out cochlear implant, only man made device so far to interact with the nervous system. It has brought hope to the deaf born child and the severely deafened individuals who can perform as well as with their normally hearing people.

Newer discoveries and surgical techniques have evolved to preserve the residual hearing to improve hearing in noise and to aid bilateral hearing. Cochlear implant is a safe surgery no longer means safety to the patient, it also means safety to the cochlea as well. A cochlear implant will not cure deafness, but is a prosthetic substitute for hearing. For people already functional in spoken language who lose their hearing, cochlear implants can be of great help in restoring functional comprehension of speech, especially if they have only lost their meaning for short time.

Minimal access technique surgeons are used to minimize retractions and reduce the size of the scar at the same time allowing the implant to be placed safely and securely. More than even now it is recognized that for good hearing performance, one should preserve residual hearing and prevent damage to the delicate cochlear structures. Although for most of the patients cochlear implant provides safe and reliable auditory benefit, occasionally patients develop problems that necessitate revision surgery includes wound infection, skin flap breakdown, device extrusion and electrode malposition.(3) Immediate device dysfunction can occur as a result of a manufacturing defect, trauma to the electrode array during insertion of the array, one case in my series electrode array went into Eustachian tube. This was noticed on postoperative $\mathrm{x}$-ray. This patient was subjected for revision surgery.

During the preparation phase for cochlear implant, surgery decision making, it is crucial to work with parents. On the expectations and feeling of accountability and fear because of possible risks.(4) some parents experience difficulties to select the best conduct to take and need help to analyze the information and experiences associated with the choice they will make as well as objective and impartial assistance to contextualize the risks and benefits in order to understand the disadvantages and advantages of the cochlear implant.(5) Early implantation prepares the brain systems for better language learning during infancy and therefore provide an earlier start in language learning. $(6,7)$

The auditory system can mature in a normal fashion only if there is adequate sound stimulation.( ${ }^{8)}$ The deprivation period of more than 03 years when the child is under 06 years restricts the normal maturation of auditory vertex. The auditory system can retain its plasticity during the period of deafness since their introduction of stimulation by the cochlear implant resumes the normal maturational sequence within the period.(8) This makes early detection and timely intervention mandatory if we want these children to join the main stream of the society and go to normal school.

Tye-murray.(9) was found that children implanted before the age of 60 months should significantly have better speech production. Similar reports stating better outcome with implantation before the age of 60 months by Connor.(10) in 2000, Geers, Nicholas in 2003.(11) and Svirsky.(12) in 2000 noticed that spoken language acquisitions better when compared to children implanted after the age of 60 months, children who receive cochlear implant at earlier age can better perform. This reflected in all the areas of speech and language development. These children can achieve better performance comparable to their normal hearing counterparts if implanted within 2 years of age.(13-17) Nowadays bilateral implants have become a highly recommended option, thus the parents has to decide not only on whether to have the implant or not, also whether the implant will be bilateral and whether it will be simultaneous or sequential.(18,19)

The most significant inhibiting factor of cochlear implant surgery is the cost of the device. It is difficult for a common man to afford a cochlear implant, maximum parents (98.3\%) said that cost was the barrier which prevented cochlear implant surgery of their child at early age. In our state, the cochlear implant surgery is covered under Aarogyasri scheme. In our institute till now we have operated more than 200 cases under Aarogyasri, in which entire cost of the implant device and AVT therapy will be covered totally free of cost for BPL families, children by State Government under 02 years of age. In my case we have achieved $99.4 \%$ success rate in cochlear implant surgery as well as in AVT therapy with a very low complication rate $(0.1 \%)$.

\section{CONCLUSION}

Cochlear implant was highly reliable and effective at providing speech understanding for patients. We have noticed that in majority of patients, cost of the implant prevented their children from receiving cochlear implant at 
the right age. The other factors that delay cochlear implant surgery are in adequate hearing screening programs for the newborns and ignorance about the importance of early intervention and referral to an implant center by patients and primary health care staff. In our state, the Government is supporting the deaf children to get cochlear implant surgery under 02 years of age under Agarogyasri program. To conclude, to resolve the factor that delay cochlear implant surgery there should be universal neonatal hearing screening facility for diagnosis, early referral and intervention for infants with hearing loss and awareness of the benefits and efficacy of cochlear implantation for children. The success of the cochlear implantation is truly the result of the team effort of the ENT surgeon, audiologist, psychologists and of course most importantly dedicated pupils and parents.

\section{REFERENCES}

1. Doyle J, Doyle D. Electrical stimulation of the nerve deafness. Bulletin of the Los Angeles Neurological Society 1963;28:148-150.

2. Hoffman RA, Cohen NL. Complications of cochlear implant surgery. Ann OtolRhinolLaryngolSuppl 1995;166:420-2.

3. Decision-making. Cochlear Implants Int. 2009; 10 Suppl 1:38-42.Disponivelem: http://www.ncbi.nim.nih.gov/pubmed/19230035

4. Hyde M, Punch R, Komesaroff L. Coming to a decision about cochlear implantation: parents making choices for their deaf children.

5. J Deaf Stud Deaf Educ 2010;15(2):162-78.

6. Hammes DM, Novak MA, Rotz LA, Willis M, Edmondson DM, Thomas JF (2002) Early identification and cochlear implantation: critical factors for spoken language development. Ann OtolRhinolLaryngolSuppl 189:74-78.

7. El-Hakim H, Levasseur J, Papsin BC, Panesar J, Mount RJ, Stevens D et al. (2001) Assessment of vocabulary development in children after cochlear implantation. Arch Otolaryngol Head Neck Surg 127:1053-1059.

8. Tomblin JB, Barker BA, Spencer I.J, Zhang X, Gantz BJ (2005) the effect of age at cochlear implant initial stimulation on expressive language growth in infants and toddlers. J speech lang Hear Res 48(4):853-867 Erratum in: J Speech Lang Hear Res. 2005 Oct;48(5):1243.
9. Effects of Deafness on the Young Brain Noise and the Brain volume null, Issue null, pages 120-154 Jos J. Eggermont.

10. Tye-Murray N, Spencer L, Woodworth GG (1995) Acquisition of speech by children who have prolonged cochlear implant experience.

J Speech Hear Res 38:327-337.

11. Connor CM, Hieber S, Arts HA, Zwolan TA (2000) speech, vocabulary, and the education of children using cochlear implants : oral or total communication. J speech Lang Hear Res:43:1185-1204.

12. Geers AE (2003) Predictors of reading skill development in children with early cochlear implantation. Ear Hear 24:46S-55S.

13. Svirsky MA, Robbins AM, Kirk KI, Pisoni DB, Miyamoto RT (2000) Language development in profoundly deaf children with cochlear implants. PsycholSci 11:153-158.

14. Communication development in children who receive the cochlear implant younger than 12 months: risks versus benefits. Ear Hear 28 (2 Suppl):11S-18S.

15. Colletti L (2009) Long-term follow-up of infants (4-11 months) fitted with cochlear implants. ActaOtolaryngol 129(4):361-366.

16. Niparko JK, Tobey EA, Thal DJ, et al. (2010) Spoken language development in children following cochlear implantation. JAMA 303(15):1498-1506.

17. Ching TY, Dillon H, Day J, et al. (2009) Early language outcomes of children with cochlear implants : interim findings of the NAL study on longitudinal outcomes of children with hearing impairment. Cochlear implants Int 10(Suppl 1):28-32.

18. Tomblin JB, Barker BA, Spencer LJ, Zhang X, Gantz BJ (2005) The effect of age at cochlear implant initial stimulation on expressive language growth in infants and toddlers. J speech Lang Hear Res 48(4):853-867.

19. Ramsden JD, Papaioannou V, Gordon KA, James AL, Papsin BC. Parental and programs decision making in paediatric simultaneous bilateral cochlear implantation: who says no and why? Int J PediatrOtorhino Laryngol 2009;73:1325-8. Dis-ponivelem: http://www.ncbi.nlm.nih.gov/pubmed/19616316.

20. Galvin KL, Leigh JR, Hughes KC. How we do it: clinical management of the child receiving a second, bilateral cochlear implant. Cochlear implants Int 2009; 10 (2): 84-91. Disponivelem: htpp://www.ncbi.nlm.nih.gov/pubmed/18949762. 